\title{
Investigating the Factors Affecting the Mammographic Density of Breast Tissue in Patients Referred to the Breast Cancer Research Center, Iran
}

\author{
Esmat Alsadat Hashemi ${ }^{1,}{ }^{*}$, Shahpar Haghighat ${ }^{2}$, Asieh Olfatbakhsh ${ }^{1}$, \\ Hoda Tafazoli Harandi ${ }^{1}$, Toktam Beheshtian ${ }^{1}$ \\ ${ }^{1}$ Breast Diseases Department, Breast Cancer Research Center, Motamed Cancer \\ Institute, ACECR, Tehran, Iran \\ ${ }^{2}$ Quality of life Department, Breast Cancer Research Center, Motamed Cancer \\ Institute, ACECR, Tehran, Iran \\ * Corresponding author: Esmat Alsadat Hashemi, Breast Diseases Department, Breast \\ Cancer Research Center, Motamed Cancer Institute, ACECR, Tehran, Iran. E-mail: \\ hashemy1277@yahoo.com
}

DOI: $10.21859 /$ mci-010212

Submitted: 22 September 2016

Revised: 18 November 2016

Accepted: 12 December 2016

ePublished: 8 March 2017

Keywords:

Breast Neoplasms

Mammography

Breast Density

\begin{abstract}
Introduction: Of the factors leading to false negative results in mammography is breast tissue density, and by increasing the density of breast tissue in mammography, the mammography sensitivity decreases. On the other hand, increasing the breast tissue density leads to increased risk of breast cancer. Various factors such as inheritance, genetics, hormonal and reproductive factors, and nutritional factors can affect the breast density, but the definitive cause of this issue is unknown. This study investigated the possible factors influencing the increase in breast tissue density in mammography.

Methods: In this cross-sectional study, a total of 428 patients were enrolled; the demographic questionnaire on variables included age, body mass index (BMI), fertility, age of menarche, taking oral contraceptive pills (OCP), menstrual status and breast size, which were completed and evaluated. To determine the relationship between the studied variables and the breast density in mammography, chi-squared test and logistic regression were used.

Results: The results showed significant correlation in age of less than 50 years, small breast cup size, low BMI, and the premenopausal status with dense view in mammography $(\mathrm{P}<$ $0.001)$. No significant relationship was observed in OCP consumption and menarche age with dense view in mammography $(\mathrm{P}>0.05)$.

Conclusions: Higher breast density in premenopausal women with low BMI may lower the sensitivity of mammography. This can underscore the importance and necessity of further controls with short intervals as well as the use of other tools for diagnosing breast cancer in these groups of patients.
\end{abstract}

(C) 2017. Multidisciplinary Cancer Investigation

\section{INTRODUCTION}

Currently, the only method of breast cancer screening which reduces the mortality of this disease is mammography. Reduction of mortality due to breast cancer screening is $22 \%$ in women over 50 years and $15 \%$ in women with 40-49 years of age [1]. This decrease in mortality is mostly due to the reduced number of diagnosed cancers in the screened population [2]. Various studies have reported the sensitivity for mammography as $65-91 \%[3,4]$. The factor that leads to false negative results in mammography is the effect of density of the breast tissue; it means that when the breast tissue density increases in mammography (dense breast), the mammographic sensitivity decreases [5]. Dense breast tissue is so common that in one study, $62 \%$ of $30-39$-year-old, $56 \%$ of $40-49$-year-old, and $37 \%$ of 50-59-year-old women had dense breast tissues [6]. On the other hand, dense breast tissue in mammography (dense breast) causes increased cancer risk.

To express the density of breast tissue in mammography, various categories have been offered such as Wolf and Tabar and absolute category rating (ACR) Breast Imaging Reporting and Data System (BIRADS) categories, and that the last classification is now used by all radiologists [1-3]. The breast tissue is extremely dense 
and can lead to unseen lesions in mammography. Breast tissue density is the strongest factor in the increased risk of breast cancer and various studies have indicated that women with a high density of breast tissue are 4-6 times in higher risk of breast cancer than women with low breast tissue density [5, 7-13].

In total, in different studies, various factors such as age, hormones usage, factors associated with parents, body mass index (BMI) and reproductive factors have been considered effective on breast tissue density, but no definitive cause for this issue is known yet [8-14].

Given that the increased density of breast tissue can lead to increased risk of breast cancer, using intervention strategies for reducing its density will be very important. For this reason, knowing the factors that have short-term effects on breast tissue density and the factors that lead to relative changes in breast density will be very important. This study aimed to investigate the possible factors influencing the breast tissue density increase in mammography in women referred to the breast Cancer Research Center of ACECR.

\section{METHODS}

In this cross-sectional study, 428 patients who were referred to the radiology ward of the Breast Cancer Research Center of ACECR for mammography in 2012 were enrolled to this study. A checklist was designed based on previous studies in addition to the possible variables affecting breast tissue density in mammography, which were approved by specialists of this field. The checklist was designed based on the study objectives; if the patients had tendency to respond, they would complete the questionnaire.

The check list comprised variables such as age, age of menarche, BMI, use of OCP, and breast size. The men- tioned variables were considered as independent variables and breast tissue density as the dependent variable. Patients who had been treated for infertility or patients with premature menopause were excluded from the study. In order to unify the report on breast tissue density in mammography, mammographic stereotypes of patients were scanned and evaluated by a radiologist. The checklists information was entered into a computer and the relationships of the studied variables as well as the density of breast tissue in mammography were evaluated. SPSS statistical software, Version 21, was used for data analysis. Mean and dispersion index were used for quantitative variables and frequency and percentage were used for qualitative variables. To evaluate the relationship between variables and the density of breast tissue, chi-squared and logistic regression tests were used.

\section{RESULTS}

In this study, a total of 428 patients were enrolled. In the analysis of data, the relationship of demographic and hormonal variables with mammographic breast tissue density was studied and it was found that among the patients, $40.4 \%$ had low-density views and $59.6 \%$ had high density views (Table 1 ). The findings of this table shows that among the studied subjects, $46.3 \%$ of patients with low tissue density and $77.3 \%$ of those with high density were less than 50 years old. Chi-squared test results showed significant correlation between age and dense mammographic view at $5 \%$ error level $(\mathrm{P}<0.001)$. In the low tissue density group, most people were 13 years old or more $(67 \%)$ and in the high density group, $42.7 \%$ were more than 13 years old. According to the study findings and the results of chi-squared test, no statistically significant relationship was observed between age of menarche and dense view in mammography $(\mathrm{P}=0.19)$ (Table 1$)$.

Table 1: Comparison of Variations in Tissue Density in Mammography Among the Studied Patients $(\mathrm{n}=428)$

\begin{tabular}{|c|c|c|c|c|}
\hline Variable & Breast Density & Iammography & $\chi^{2}$, Test Value & P Value \\
\hline & High Density, $(\mathrm{n}=255)$, No. $(\%)$ & Low Density, $(\mathrm{n}=173)$, No. $(\%)$ & & \\
\hline Age & & & 47.68 & $<0.001$ \\
\hline$<50$ & $197(77.3)$ & $80(46.3)$ & & \\
\hline $50-54$ & $40(15.8)$ & $35(20.3)$ & & \\
\hline $55-59$ & $33(19.2)$ & $15(8.7)$ & & \\
\hline$>60$ & $20(11.8)$ & $8(4.7)$ & & \\
\hline Age of Menarche & & & 4.81 & 0.19 \\
\hline$<12$ & $26(10.2)$ & $15(8.6)$ & & \\
\hline 12 & $51(20)$ & $42(24.4)$ & & \\
\hline 13 & $69(27.1)$ & $58(33.5)$ & & \\
\hline$>13$ & $109(42.7)$ & $58(33.5)$ & & \\
\hline OCP Use & & & 2.01 & 0.16 \\
\hline No & $159(62.3)$ & $96(55.5)$ & & \\
\hline Yes & $96(37.7)$ & $77(44.5)$ & & \\
\hline Breast Cup Size & & & 25.32 & $<0.001$ \\
\hline A & $24(9.4)$ & $9(5.2)$ & & \\
\hline B & $80(31.4)$ & $26(15.1)$ & & \\
\hline $\mathrm{C}$ & $62(24.3)$ & $39(22.5)$ & & \\
\hline $\mathrm{D}$ & $89(34.9)$ & $99(57.2)$ & & \\
\hline
\end{tabular}

*Significant at the level of $5 \%$. 
Among the studied subjects, 255 (59.5\%) were not using OCP pills. Most of these individuals (62.3\%) were in the high density group. Based on the findings and the chi-squared test results of table 1 , no significant relationship was observed between the variable of OCP usage and dense view. One hundred eighty eight cases (43.9\%) had a breast cup size of D and among them, 99 subjects were in the low density group. According to the chi-squared test results in Table 1, a statistically significant relationship was observed between breast cup size and mammographic dense view $(\mathrm{P}<0.001)$. According to the findings in Table 2, 191 patients (44.6\%) of all the participants had BMIs of 25-29, who were accounted for the highest percentage in the BMI index levels. At this level of BMI, most of the people (121) were in the high density group. According to the result of Fisher's exact test, a significant relationship between BMI index and mammographic dense view was observed at the level of 5\% ( $\mathrm{P}<0.001)$. Two hundred forty seven cases $(57.7 \%)$ of all the participants were in the regular menstruation, which had the highest frequency. Also, in the group with high density tissue in mammography, most subjects had regular menstrual statuses (65.5\%). According to results of table 2, the fewest number is assigned for people with hysterectomy.

Logistic regression was used to analyze the data and for this purpose, the variables were defined based on the distribution and biology of the effect of factors on breast tissue density as binary variables. After univariate analysis, the independent variables that had shown statistically significant relationships at 5\% alpha error with breast tissue density were entered into multivariate logistic regression model. Results of multivariate logistic regression analysis showed that the odds ratio of dense breast tissue in women with BMIs of less than 25 to 25 and higher is 2.2 with $95 \%$ confidence interval (1.2533.909). Furthermore, the odds ratio of dense breast tissue in $A$ and $B$ cup sizes to $C$ and $D$ sizes and age younger than 50 to 50 years and higher were respectively 1.99 (1.2-3.32) and 3.6 (2.22-5.81) (Table 3).

Table 2: Correlation of Variables of BMI and Menstrual Status With Mammographic Tissue Density

\begin{tabular}{|c|c|c|c|c|}
\hline \multirow[t]{2}{*}{ Variable } & \multicolumn{2}{|c|}{ Breast Density in Mammography } & \multirow[t]{2}{*}{ F Test Value, Fishers Exact Test } & \multirow[t]{2}{*}{ P Value } \\
\hline & High Density $(n=255)$, No. $(\%)$ & Low Density $(n=173)$, No. $(\%)$ & & \\
\hline BMI & & & 34.93 & $<0.001$ \\
\hline$<20$ & $7(2.7)$ & $1(0.5)$ & & \\
\hline $20-24$ & $75(29.4)$ & $24(13.9)$ & & \\
\hline $25-29$ & $121(47.5)$ & $70(40.5)$ & & \\
\hline$\geq 30$ & $52(20.4)$ & $78(45.1)$ & & \\
\hline Menstrual Status & & & 26.89 & $<0.001$ \\
\hline Regular & $167(65.5)$ & $80(46.3)$ & & \\
\hline Irregular & $44(17.2)$ & $25(14.5)$ & & \\
\hline Menopause & $42(16.5)$ & $67(38.7)$ & & \\
\hline Hysterectomy & $2(0.8)$ & $1(0.5)$ & & \\
\hline
\end{tabular}

Results of Fisher's exact test show the significant correlation of menstrual status with mammographic tissue density at the level of $5 \%$ $(\mathrm{P}<0.001)$.

Table 3: Results of Multivariate Logistic Regression Analysis) Factors Affecting the Density of Breast Tissue

\begin{tabular}{|c|c|c|c|c|}
\hline Variable & B & SD & OR (\%95 CI $)$ & P Value \\
\hline \multicolumn{5}{|l|}{ BMI } \\
\hline$<25$ Compare to $\geq 25$ & 0.794 & 0.29 & $(1.253-3.909) 1.999$ & $0.006^{*}$ \\
\hline \multicolumn{5}{|l|}{ Breast Cup Size } \\
\hline A \& B Compare to C \& D & 0.693 & 0.259 & $(1.204-3.319) 1.999$ & $0.007^{*}$ \\
\hline \multicolumn{5}{|l|}{ Age } \\
\hline$<50$ Compare to $\geq 50$ & 1.278 & 0.246 & $(2.217-5.809) 3.588$ & $<0.001^{*}$ \\
\hline \multicolumn{5}{|l|}{ Menstrual Status } \\
\hline Regular Compare to Irregular \& Menopause \& Hysterectomy & 0.241 & 0.239 & $(0.796-2.033) 1.272$ & 0.313 \\
\hline
\end{tabular}




\section{DISCUSSION}

Radiological appearance of breast tissue in mammography reflects difference in breast tissue composition in different people. In mammography view, fatty tissue is seen as radiolucent or dark, and epithelial and stromal view is seen as just radiodense or bright. Depending on the degree of darkness or lightness of mammographic density of breast tissue view, it is considered from No. I- IV with the ACR scale. Generally, ACR I and II are considered as breast tissues with low density and ACR III-IV as breast tissues with high density. Mammographic tissue density is one of the strongest factors for increased risk of breast cancer. In fact, women with a high mammographic density breast tissue are almost five times at higher risk of developing breast cancer than women with low mammographic density [5, 15-17]. According to studies, breast tissue density is influenced by various factors such as age, menopause, fertility, BMI, and hormonal and nutritional factors $[18,19]$.

The study of Lundberg et al. on the effect of infertility treatment on mammographic density showed that compared to women with no hormone treatment, infertile women who received hormonal fertility treatment had higher mammographic density [20]. In a study by Nevler et al., 2760 screening mammograms were performed. Results showed that women with denser breast tissues required further screening methods like sonography and more investigations such as tissue biopsy. In these women, the incidence of cancer is likely higher [21].

Since several factors affect the amount of mammographic density and according to conducted surveys until now no research has been conducted in this case in Iran, this study was designed to investigate the factors affecting the density of breast tissue in women referred to the breast clinic of ACECR. Different variables were studied and the relationship between them as well as mammographic density was investigated. In the following, we are going to discuss about them.

Overall, 428 women who underwent mammography in the Radiology Ward of ACECR's breast clinic were enrolled in the study and a questionnaire containing the interest variables was completed for each patient. The relationship between the studied variables and the density of breast tissue in mammography was evaluated in the conducted statistical analysis.

In classification of the breast tissue density by integrating the density, ACR I and ACR II were seen as low density and ACR III and ACR IV as high density; about $40 \%$ of patients (173) had low-density breast tissue and 255 (60\%) had high-density tissue. The obtained frequency in this study corresponds with international studies [22].

Of the studied variables, age factor can be noted; based on the results of the study, with aging, density of the breast tissue decreases; in this study, age of under 50 years was associated with the highest density of breast tissue and after that age, breast tissue density decreased. This issue is also match up with menopause, meaning that by menopause and increase of its duration, the density of breast tissue reduces. This seems logical because with aging and menopause, by the decreasing levels of ovarian hormone, the hormonal effect of ovary on breast tissue is reduced, which also results in the reduction of epithelial tissue of the breast tissue and its replacement with fatty tissue. Similar results have been reported in other studies [8].

Menarche age is another variable; according to the results, with increasing menarche age dense view also increases. The highest density (25.5\%) can be seen in subjects with maturity age of above 13 years. Research findings show an upward trend in age of menarche of subjects in both low-density and high-density groups, but in chi-squared test, no significant relationship was observed between menarche age and mammographic dense view. On the other hand, individuals with regular menstruation have the highest frequency of tissue density (39\%). Fisher's exact test showed a significant association between menstruation and dense view. By regular effect of ovarian hormone on breast tissue, hyperplasia of breast epithelial tissue occurs, which leads to an increase in mammographic density; while, the increase of menarche age and irregularity of menstruation leads to lower effect of ovarian hormone on breast tissue and as a result breast tissue density reduces in mammography.

According to the results of this study, no significant relationship was observed between OCP usage and breast density. It is possible that duration and type of OCP usage affect the breast tissue density, which was not investigated in this study. According to the results, a statistically significant relationship was observed between breast cup size and dense view in mammography. This means that by increasing the size of breast, density of breast tissue reduces in mammography; this relationship was also observed for BMI. It was also found that in BMIs of 25-29, most of the cases (121 subjects) $(28.3 \%)$ were in the high-density group and Fisher's exact test showed a significant association between BMI and dense view in mammography. These results also correspond with the study of Riza [12]. Overall, of the studied variables, age, BMI and breast cup size showed inverse relationships with density of breast tissue in mammography, while menstrual status can have a direct effect on the density of breast tissue in mammography. The results showed that in young and thin women with smaller breast sizes and regular menstruations, breast tissue was denser and consequently the risk of breast cancer will be higher. In these cases, it is necessary that, if needed, doctors and patients pay more attention to performing periodic checkups at shorter intervals and the use of radiology diagnostic methods and more efforts should be made by the health care system in the 
field of information and providing the necessary trainings to this group of people.

\section{ACKNOWLEDGEMENTS}

This work was supported by a grant from the ACECR. This article was a translated version of the Persian article which has been published in Iranian Quarterly Journal of Breast Diseases, Volume 7, Number 3.

\section{CONFLICTS OF INTEREST}

The authors declare that they have no conflict of interests.

\section{ETHICS APPROVAL}

The research plan for this study was registered and approved by the Ethics Committee of Breast Cancer Research Center of ACECR.

\section{REFERENCES}

1. Wolfe JN. Breast patterns as an index of risk for developing breast cancer. AJR Am J Roentgenol. 1976;126(6):1130-7. DOI: $10.2214 /$ ajr.126.6.1130 PMID: 179369

2. Wolfe JN. Breast parenchymal patterns and their changes with age. Radiology. 1976;121(3 Pt. 1):545-52. DOI: 10.1148/121.3.545 PMID: 981644

3. Tabar L, Dean PB. Mammographic parenchymal patterns. Risk indicator for breast cancer? JAMA. 1982;247(2):185-9. PMID: 7053455

4. Elmore JG, Nakano CY, Koepsell TD, Desnick LM, D’Orsi $\mathrm{CJ}$, Ransohoff DF. International variation in screening mammography interpretations in community-based programs. J Natl Cancer Inst. 2003;95(18):1384-93. PMID: 13130114

5. McCormack VA, dos Santos Silva I. Breast density and parenchymal patterns as markers of breast cancer risk: a meta-analysis. Cancer Epidemiol Biomarkers Prev. 2006; 15(6):1159-69. DOI: 10.1158/1055-9965.EPI-06-0034 PMID: 16775176

6. Warner E, Lockwood G, Tritchler D, Boyd NF. The risk of breast cancer associated with mammographic parenchymal patterns: a meta-analysis of the published literature to examine the effect of method of classification. Cancer Detect Prev. 1992;16(1):67-72. PMID: 1532349

7. Vachon CM, Brandt KR, Ghosh K, Scott CG, Maloney SD, Carston MJ, et al. Mammographic breast density as a general marker of breast cancer risk. Cancer Epidemiol Biomarkers Prev. 2007;16(1):43-9. DOI: 10.1158/1055-9965.EPI-060738 PMID: 17220330

8. Checka CM, Chun JE, Schnabel FR, Lee J, Toth H. The relationship of mammographic density and age: implications for breast cancer screening. AJR Am J Roentgenol. 2012;198(3):W292-5. DOI: 10.2214/AJR.10.6049 PMID: $\underline{22358028}$
9. Sung J, Song YM, Stone J, Lee K, Kim SY. Association of body size measurements and mammographic density in Korean women: the Healthy Twin study. Cancer Epidemiol Biomarkers Prev. 2010;19(6):1523-31. DOI: 10.1158/1055-9965. EPI-09-1005 PMID: 20501766

10. El-Bastawissi AY, White E, Mandelson MT, Taplin SH. Reproductive and hormonal factors associated with mammographic breast density by age (United States). Cancer Causes Control. 2000;11(10):955-63. PMID: 11142530

11. Wu AH, McKean-Cowdin R, Tseng CC. Birth weight and other prenatal factors and risk of breast cancer in Asian-Americans. Breast Cancer Res Treat. 2011;130(3):917-25. DOI: 10.1007/s10549-011-1640-x PMID: 21710135

12. Riza E, Remoundos DD, Bakali E, Karadedou-Zafiriadou E, Linos D, Linos A. Anthropometric characteristics and mammographic parenchymal patterns in post-menopausal women: a population-based study in Northern Greece. Cancer Causes Control. 2009;20(2):181-91. DOI: 10.1007/s10552-0089232-8 PMID: 18814046

13. Skippage P, Wilkinson L, Allen S, Roche N, Dowsett M, A'Hern R. Correlation of age and HRT use with breast density as assessed by Quantra. Breast J. 2013;19(1):79-86. DOI: 10.1111/tbj.12046 PMID: 23230974

14. Andersson I, Janzon L, Pettersson H. Radiographic patterns of the mammary parenchyma: variation with age at examination and age at first birth. Radiology. 1981;138(1):59-62. DOI: $\underline{\text { 10.1148/radiology.138.1.7455098 PMID: } 7455098}$

15. Boyd NF, Martin LJ, Bronskill M, Yaffe MJ, Duric N, Minkin S. Breast tissue composition and susceptibility to breast cancer. J Natl Cancer Inst. 2010;102(16):1224-37. DOI: 10.1093/ inci/djq239 PMID: 20616353

16. Johns PC, Yaffe MJ. X-ray characterisation of normal and neoplastic breast tissues. Phys Med Biol. 1987;32(6):675-95. PMID: 3039542

17. Boyd NF, Guo H, Martin LJ, Sun L, Stone J, Fishell E, et al. Mammographic density and the risk and detection of breast cancer. N Engl J Med. 2007;356(3):227-36. DOI: $10.1056 /$ NEJMoa062790 PMID: 17229950

18. Boyd NF, Martin LJ, Rommens JM, Paterson AD, Minkin S, Yaffe MJ, et al. Mammographic density: a heritable risk factor for breast cancer. Methods Mol Biol. 2009;472:343-60. DOI: 10.1007/978-1-60327-492-0_15 PMID: 19107441

19. Boyd NF, Rommens JM, Vogt K, Lee V, Hopper JL, Yaffe MJ, et al. Mammographic breast density as an intermediate phenotype for breast cancer. Lancet Oncol. 2005;6(10):798-808. DOI: $10.1016 /$ S1470-2045(05)70390-9 PMID: 16198986

20. Lundberg FE, Johansson AL, Rodriguez-Wallberg K, Brand JS, Czene K, Hall P, et al. Association of infertility and fertility treatment with mammographic density in a large screening-based cohort of women: a cross-sectional study. Breast Cancer Research. 2016;18(1):1.

21. Nevler A, Shabtai E, Rosin D, Hoffman A, Gutman M, Shabtai M. Mammographic Breast Density as a Predictor of Radiological Findings Requiring Further Investigation. Isr Med Assoc J. 2016;18(1):32-5. PMID: 26964277

22. Razzaghi H, Troester MA, Gierach GL, Olshan AF, Yankaskas BC, Millikan RC. Mammographic density and breast cancer risk in White and African American Women. Breast Cancer Res Treat. 2012;135(2):571-80. DOI: 10.1007/s10549-0122185-3 PMID: 22864770 